\title{
PASSIVE TRANSFER ANTIBODIES FOR SIX SAPROPHYTIC FUNGI IN A PATHENT WITH A SUPERFICIAL SCALING DERMATOSIS
}

\author{
By ELBERT L. PERSONS AND DONALD S. MARTIN \\ (From the Departments of Medicine and Bacteriology, Duke University School \\ of Medicine, Durham)
}

(Received for publication April 1, 1936)

Recent interest in the relationship of fungi to human disease, both as infecting agents and as incitants of phenomena of hypersensitivity, induced us to undertake a detailed study of a patient who presents an uncommon skin lesion which appears to be associated with sensitivity to at least six species of non-pathogenic fungi. Passive transfer antibodies for these fungi were present in the patient's serum, and their reciprocal neutralization by three members of different genera of fungi is of mycologic interest.

\section{CASE REPORT}

The patient, a pathologist of 33 , gives no history of hay fever, asthma or other manifestations of hypersensitivity in himself or in his large family, of which he has an unusually detailed knowledge. In September, 1933, he noticed a small follicular papule on the anterior surface of the right mid-thigh. Pus was expressed from this lesion several times, but no distinctive features were noted until late in November, when the lesion, superficial and scaling, involved an area the size of a dime. It was then covered intermittently with adhesive tape, and by December 28 had involved the whole area to which adhesive had been applied.

On January 3,1934, several similar plaques from 1 to $3 \mathrm{~cm}$. in diameter appeared on the extensor surfaces of the extremities. The evolution of these lesions was very rapid and was associated with intense pruritis.

When first seen on January 12, the original lesion was an irregularly circular, yellowish red, partially denuded and slightly moist area of $4 \times 6 \mathrm{~cm}$. There was no tenderness or infiltration and nothing to suggest vesicle or pustule formation. The border was not palpable and showed nothing but adherent scales. The process seemed to be entirely confined to the epidermis, and there was nothing to suggest a follicular distribution. About a dozen similar, but dry, yellowish, and apparently even more superficial, round lesions, varying from 2 to $4 \mathrm{~cm}$. in diameter, were present on the lateral surfaces of the arms, the extensor surfaces of the forearms and the lateral surfaces of the buttocks and thighs. At this time scrapings from the original lesion and from eight of the more recent lesions were inoculated on Sabouraud's glucose agar plates.

One of the eight plates inoculated from the newer lesions became contaminated with a peripheral "spreader" after several days of observation, and was discarded. No fungus growth appeared on the other seven plates during two weeks of observation, and duplicate cultures from three of these lesions were again negative. The plate inoculated from the original lesion showed numerous colonies of fungi, many of them seeming to arise from the point at which a scale had been deposited. The colonies grew very rapidly but it was possible to isolate seven culturally distinct fungi, all having the appearance of non-pathogenic organisms which have been found on the normal skin (1).

These seven strains have been identified with the assistance of Dr. F. A. Wolfe ${ }^{1}$ and Dr. N. F. Conant.

Strain 1. Cryptococcus. Group IV (pink), Type A, Benham (2).

Strain 2. Cladosporium herbarum.

Strain 3. Cladosporium sp. The culture of this strain became contaminated before it could be identified, but examination of a stained smear of the material prepared for skin tests showed fruiting bodies typical of Cladosporium. In the gross, the colony was distinctly different from that of $C$. herbarum.

Strain 4. Unidentifiable. This fungus produced a sterile interwoven septate mycelium having no striking characteristics. Sabouraud's glucose agar medium became wine-colored due to the production of pigment. Since no spore forms were produced in culture this strain must be classified with the Mycelia sterila. The organism appears to be of a type described by mycologists as an occasional contaminant.

Strain 5. Penicillium roseo-citreum.

Strain 6. Nigrospora sp. No attempt to determine the species has been made.

Strain 7. Aspergillus fumigatus.

The forty-eight hour growth of each fungus was scraped from a Sabouraud's slant and ground in a mortar to break up the larger particles. Sufficient saline was added to produce a slightly cloudy suspension (approximately 0.1 per cent by volume), and the individual suspensions were then sterilized by heating for three hours at $60^{\circ} \mathrm{C}$. An intracutaneous test with a mixture of these suspensions produced a large immediate wheal on the patient's forearm, with definite pseudopod formation. There was no delayed local reaction at the point of injection but an increase of the pruritis in all the skin lesions was reported. Intracutaneous tests with the pink Cryptococcus produced only an immediate erythema. Each of the other six heat-killed suspensions produced

1 Department of Botany, Duke University. 
an immediate wheal with pseudopods, although these reactions were uniformly smaller than that produced by the mixture. Again, there was no delayed local reaction, but increased itching of the skin lesions was reported.

Blood was drawn for passive transfer tests and then graduated subcutaneous injections of a 1:1000 dilution of the mixture were started. These were followed by such a definite increase in the activity of all the skin lesions that the patient has, until the present time, refused further therapeutic injections and prefers Roentgen ray therapy.

The original lesions healed after this treatment, but one or more superficial, pruritic, scaling areas have recurred at intervals of two or three months, involving different areas on the back of the right hand and on the posterior surfaces of the legs, at, or just above the sockline. One such outbreak occurred in February, 1935, ten days after the second sample of blood was obtained, and another occurred in January, 1936, about three weeks before the final sample was drawn. The lesions show no tendency to spontaneous resolution but respond readily to Roentgen rays, disappearing without evidence of atrophy or destruction of the hair follicles. There has been no recurrence of the primary lesion, and no lesion has appeared recently on an area completely protected by clothing. No clinical evidence of dermatophytosis has ever been present but a skin test to trichophytin (Metz), 1:100, was positive after forty-eight hours; no immediate wheal appeared.

\section{Passive transfer tests}

\section{Experiment I}

Serum drawn on January 25, 1934, was used within two days of withdrawal to prepare seven sites on the back of each of two subjects ( $P$ and M). Forty-eight hours later $0.05 \mathrm{cc}$. of each suspension of heat-killed organisms, with the exception of the mixed suspension, was injected in each of the prepared sites respectively and in an adjacent control area. No significant reaction to the pink Cryptococcus occurred in either subject. Moderate passive transfer reactions (wheals less than $1 \mathrm{~cm}$. in diameter but with definite pseudopods and a marked erythema of 2 to $3 \mathrm{~cm}$.) occurred in each subject to Cladosporium herbarum and to Penicillium roseo-citreum. Suspensions of the remaining four organisms gave uniformly larger, strongly positive reactions, and the same areas of skin were sensitive to the same amount of antigen forty-eight hours later. All controls were negative. The passive sensitivity was found to persist for at least four weeks.

\section{Experiment II}

On January 24, 1935, another sample of serum was obtained from the patient and a control sample was drawn from another subject who had a somewhat similar skin lesion but did not react to the mixture of heat-killed organisms.

On February 1, twenty-one sites on the back of Subject $\mathrm{H}$ were prepared; the control serum was used in seven, the serum of Experiment I, now 372 days old, in seven, and the fresh serum in the remaining seven. After forty-eight hours $0.05 \mathrm{cc}$. each of the seven antigen suspensions was injected at sites which had been prepared with each of the three sera respectively and into an area of normal skin. No positive reactions appeared in the untreated areas, or in the sites prepared with the control serum. The old and new samples of the patient's serum, however, appeared to be equally potent in sensitizing this subject's skin. Again, the pink Cryptococcus suspension produced no wheal, while the remaining six suspensions produced moderate to marked reactions in the sensitized areas.

The serum of Experiment I was tested a third time after storage for 656 days in the icebox and was found to have lost its sensitizing power.

\section{Neutralization tests}

The demonstration of passive transfer antibodies for six different saprophytic fungi in the serum of an otherwise non-allergic man of thirtythree suggested the possibility that a single reacting substance might be present, particularly when the fungi involved were cultured from a single skin lesion. The neutralization of reagin in vivo is now a standard method of testing the identity of atopens, and it has also been shown that in vitro neutralization occurs if the reagin is mixed with a suitable amount of the related atopen (3). Experiments were planned to test the unity of the reagin by both methods, in which three of the fungi, Cladosporium herbarum, Nigrospora sp. and Aspergillus fumigatus were used.

\section{Experiment III}

Twelve sites were sensitized by the injection of $0.15 \mathrm{cc}$. of the patient's serum. Three sites were left untouched, and the remaining nine divided into three groups. The reacting power of each 
group to one of the fungus suspensions was exhausted by the repeated injection, at intervals of 7 to 8 hours, of the appropriate antigen in amounts of $0.1 \mathrm{cc}$. Not more than three injections were needed in any site, and the final testing was done twenty hours after the last injection and fortyeight hours after the sensitizing serum had been given.

TABLE I

Experiment III. In vivo neutralization by repeated injection of the sensitized site

\begin{tabular}{|c|c|c|c|}
\hline \multirow[b]{2}{*}{$\begin{array}{l}\text { Site sensitized on } \\
\text { Subject G and: }\end{array}$} & \multicolumn{3}{|c|}{ Tested with suspension of: } \\
\hline & $\begin{array}{l}\text { Clado- } \\
\text { sporium } \\
\text { herbarum }\end{array}$ & Nigrospora & $\begin{array}{l}\text { Aspergillus } \\
\text { fumigatus }\end{array}$ \\
\hline $\begin{array}{l}\text { Exhausted with Cladosporium } \\
\text { herbarum } \\
\text { Exhausted with Nigrospora sp. } \\
\text { Exhausted with Aspergillus } \\
\text { fumigatus }\end{array}$ & $\begin{array}{l}\text { Negative } \\
\text { Negative } \\
\text { Negative }\end{array}$ & $\begin{array}{l}\text { Negative } \\
\text { Negative } \\
\text { Negative }\end{array}$ & $\begin{array}{l}\text { Negative } \\
\text { Negative } \\
\text { Negative }\end{array}$ \\
\hline $\begin{array}{l}\text { Controls-sensitized but not } \\
\text { treated with antigen }\end{array}$ & $\begin{array}{l}\text { Large wheal } \\
\text { pseudopods } \\
\text { erythema }\end{array}$ & $\begin{array}{l}\text { Large wheal } \\
\text { pseudopods } \\
\text { erythema }\end{array}$ & $\begin{array}{l}\text { Large wheal } \\
\text { pseudopods } \\
\text { erythema }\end{array}$ \\
\hline
\end{tabular}

Table I shows the results of the final tests and indicates complete cross-neutralization in all directions.

The experiment is open to the criticism that there was no control of the possibility of nonspecific exhaustion of the reacting capacity of the skin, or that the time interval between injections of antigen was too short. In a previous experiment of a similar nature on the same subject the reactions of the test areas were, after an interval of seventy-two hours, identical with those described above, but unfortunately the sensitized control areas could not be found because their marking had worn off. Furthermore, when this subject was used in the preliminary part of Experiment IV, we repeatedly observed large wheal reactions in areas in which a similar wheal had been produced seven to eighteen hours previously. Consequently, none of our results support the idea of an exhaustion of the skin by non-specific means.

\section{Experiment IV}

In in vitro neutralization tests it was found, in a preliminary experiment, that a mixture of two parts of the patient's serum with one part of Cladosporium herbarum suspension was capable of sensitizing normal skin but that equal parts of the two materials resulted in a mixture which did not sensitize. When suspensions of Nigrospora and Aspergillus fumigatus were used, however, equal parts of serum and suspensions resulted in mixtures capable of producing passive sensitization; two volumes of the antigen were necessary to neutralize the reagin.

Mixtures of a fresh sample of the patient's plasma and each of the suspensions, in proportions appropriate for neutralization, were made and incubated at $37^{\circ} \mathrm{C}$. for one hour. Since mixtures of serum or plasma and saline solution which have been treated in this manner produce a non-specific immediate reaction when injected intracutaneously, it was necessary to control the effect of this primary cutaneous reaction on later passive sensitivity. An incubated mixture of equal parts of the patient's plasma and a heatkilled saline suspension of Rhizopus was also included as a control. The back of Subject $P$, who had not been used for 287 days, was prepared on February 5, 1936, and tested sixty-five hours later.

TABLE II

Experiment IV. In vitro neutralization of reagin in the patient's plasma by fungus suspensions

\begin{tabular}{|c|c|c|c|}
\hline $\begin{array}{l}\text { Site prepared with } \\
0.1 \text { cc. of mixture }\end{array}$ & $\begin{array}{l}\text { Reaction } \\
\text { from } \\
\text { mixture }\end{array}$ & $\begin{array}{l}\text { Site tested after } \\
65 \text { hours with }\end{array}$ & Reaction \\
\hline $\begin{array}{l}\text { Cladosporium } \\
\text { + plasma } \\
\text { (equal parts) }\end{array}$ & & $\begin{array}{l}\text { Cladosporium } \\
\text { Nigrospora } \\
\text { Aspergillus }\end{array}$ & $\begin{array}{l}\text { Negative } \\
\text { Negative } \\
\text { Negative }\end{array}$ \\
\hline $\begin{array}{l}\text { Nigrospora } \\
\quad(2 \text { parts })+ \\
\quad \text { plasma }(1 \text { part })\end{array}$ & & $\begin{array}{l}\text { Cladosporium } \\
\text { Nigrospora } \\
\text { Aspergillus }\end{array}$ & $\begin{array}{l}\text { Negative } \\
\text { Negative } \\
\text { Negative }\end{array}$ \\
\hline $\begin{array}{l}\text { Aspergillus } \\
\quad(2 \text { parts })+ \\
\text { plasma (1 part) }\end{array}$ & & $\begin{array}{l}\text { Cladosporium } \\
\text { Nigrospora } \\
\text { Aspergillus }\end{array}$ & $\begin{array}{l}\text { Negative } \\
\text { Negative } \\
\text { Negative }\end{array}$ \\
\hline
\end{tabular}

Controls

\begin{tabular}{|c|c|c|c|}
\hline $\begin{array}{l}\text { Rhizopus } \\
\text { + plasma } \\
\text { (equal parts) }\end{array}$ & $\begin{array}{l}+t+ \\
++t \\
+t+\end{array}$ & $\begin{array}{l}\text { Cladosporium } \\
\text { Nigrospora } \\
\text { Aspergillus }\end{array}$ & $\begin{array}{l}+t+t \\
+t+t \\
+t+t\end{array}$ \\
\hline $\begin{array}{c}\text { Saline }+ \text { plasma } \\
\text { (equal parts) }\end{array}$ & & $\begin{array}{l}\text { Cladosporium } \\
\text { Nigrospora } \\
\text { Aspergillus } \\
\text { Rhizopus }\end{array}$ & $\begin{array}{l}++++ \\
++++ \\
+++t \\
\text { Negative }\end{array}$ \\
\hline
\end{tabular}

As shown in Table II, the mixtures of plasma and saline solution and of plasma and suspension of Rhizopus produced large wheals which attained maximum size within fifteen minutes; at 
these sites normal passive transfer reactions were later demonstrated. The mixtures of plasma and passive transfer antigens, however, produced even larger wheals, which increased in size for about thirty minutes and were still visible as marked erythematous areas after one hour; in these areas no further skin sensitivity could be shown.

The experiment just described was repeated on Subject $H$, serum instead of plasma being used; the results were the same.

Passive transfer tests, the patient's serum and other antigens than those obtained from him being used, have been done with the following results : Trichophytin (Metz) 1:100 dilution, negative in two subjects; Rhizopus (from dust), negative in three subjects; Alternaria (from dust), positive in two of three subjects; Monilia albicans extract (Lederle, 1:100), positive in two subjects; Saccharomyces cerevisiae, negative in one subject.

Patch tests to the fungus suspensions have not been carried out on the patient because of the possibility of causing a relatively mild process in the skin to become distressing.

\section{DISCUSSION}

The dermatosis present in this case resembled a trichophytid seen occasionally in conjunction with severe fungus infections of the feet. No such infection was present, and the character of the primary lesion on the thigh did not suggest an infection with a pathogenic fungus. From a dermatologic standpoint, then, we were dealing with lesions having many of the characteristics of conditions exemplified by trichophytids, which appeared soon after the development of an epidermal reaction around a chronic pustule. It is true that the rapid growth of the saprophytic molds found in this lesion might have inhibited the growth, or prevented the recognition, of types of fungi known to be pathogens. We do not imply that the fungi found produced the original lesion, and have no direct evidence that they were even growing in the skin. However, the rather extraordinary finding of no fungi in seven of the secondary lesions suggested that the isolation of seven fungi from the primary lesion might be of significance. The demonstration of the passive transfer immediate-wheal type of sensitivity to six of them, the focal reactions following attempts at subcutaneous hyposensitization, and the subsequent recurrence of lesions on relatively exposed areas of skin all lead to the belief that sensitization to saprophytic fungi was an important etiological factor in the manifestations which occurred in our patient following the appearance of the original lesion.

Hilgermann, in 1921 (4), described focal reactions in patients with chronic eczema after injections of vaccines made from cultures of organisms obtained from the lesions, e.g., Aspergillus, Mucor, Yeasts and Streptothrix, and numerous types of bacteria. In 1930, Hopkins, Kesten and Benham $(5,6)$ recorded the case of a man of thirty-seven who gave a history of asthma since childhood and eczema involving exposed areas of skin since the age of twenty-five. Both had cleared up entirely during a sea voyage. "Immediate intradermal reactions" were obtained with extracts of Aspergillus nidulans grown from an eczematous area, and of an Alternaria and several other fungi grown from dusts. Asthma appeared following the inhalation of spores of these fungi, and " on several occasions following the production of asthma by Alternaria spray.a patch of eczema became acutely inflamed." Passive transfer was demonstrated for Alternaria extract, but no such test with Aspergillus nidulans was reported, and patch tests with extracts of the latter were inconclusive. By the routine use of skin tests to extracts of saprophytic fungi in the study of eczema they obtained positive results in twenty-three other patients, five of which improved after a change of environment (7).

Brown (8) reported the cases of two girls of fourteen with eczema occurring on exposed surfaces since infancy, who gave positive cutaneous tests to Aspergillus fumigatus; one reacted to tests with Saccharomyces cerevisiae. His report and several others $(9,10,11)$ indicate that molds are now widely recognized as capable of producing asthma and hay fever in sensitive individuals. Our studies on this case furnish more evidence in favor of the recognition of saprophytic fungi as possible incitants of skin lesions.

Passive transfer reagins are usually present in the serum when the offending antigen produces an immediate wheal in the skin of the sensitive indi- 
vidual. Such antibodies have not been demonstrated in cases of contact dermatitis, nor in cases with the delayed, tuberculin type of hypersensitiveness. They are almost constantly present in the hereditary forms of allergy, such as hay fever and asthma. Consequently, the finding of these reagins in a patient with hypersensitiveness should lead to careful consideration of a possible hereditary factor.

It is, however, well known $(12,13)$ that contact or infestation with Ascaris and other worms parasitic on man may produce a lasting skin sensitivity associated with passive transfer substances, irrespective of any hereditary predisposition. Also, Sulzberger and Kerr (14) and Tomlinson (15) have each found one case in which passive transfer reagins for trichophytin persisted for a long time and in which no hereditary factors were present. Each patient had suffered from active dermatophytosis of the feet. Such instances must be very rare, since dermatophytic infection usually produces the delayed, tuberculin type of skin sensitivity; the fungi cannot now be classed with the roundworms as agents which characteristically produce passive transfer reagins. Thus, it seems impossible at the present time to classify the type of hypersensitiveness shown by our patient.

The significance of our failure to demonstrate, by neutralization tests in the skin or in the test tube, more than one substance mediating passive transfer sensitivity to such a variety of fungi as Cladosporium herbarum, Aspergillus fumigatus and the Nigrospora strain is difficult to estimate, since no reports are available which can be interpreted as confirming such a finding. Much evidence supports the attitude expressed by Coca and Grove (3) that, " in the blood of individuals sensitive to more than one substance, more than one reagin can be demonstrated." Consequently, our failure to demonstrate multiple reagins speaks for the biologic identity of some substance common to these suspensions. On the other hand, according to the usual morphologic criteria of mycology, these three genera have nothing in common, except the conidia and aerial hyphae which suffice only to place them in the same large order, "Moniliales," of the Fungi Imperfecti.

It should be noted that we have worked with suspensions of heat-killed organisms from Sabouraud's agar slants, whereas most other work has been done with powdered felts, with filtered extracts of the fungi or the broth in which they were grown. Our negative results with Rhizopus and Saccharomyces serve as controls for the medium used, and the simplicity of the methods employed leaves no other obvious source of error.

The group specificity noted in hypersensitiveness to trichophytin (16) suggests a much closer relationship between the dermatophytes than can be demonstrated by morphologic study. Our results indicate that a common substance is present in genera of non-pathogenic fungi which are morphologically unrelated. Perhaps further studies along these lines may be of value in establishing a more satisfactory grouping of the Fungi Imperfecti than present criteria allow. We believe that our findings suggest a closer relationship between the genus Aspergillus and the genus Cladosporium than is indicated by the present mycologic classification, which places them in separate families on the basis of the "brightness" or "darkness" of the hyphae and conidia.

\section{SUMMARY}

A man of thirty-three, who gave no history of hypersensitiveness in himself or his family was found to have developed a generalized pruritic scaling dermatosis about five weeks after the appearance of an epidermal reaction around a pustule on the thigh. Culture of the initial lesion, after the dermatosis had appeared, resulted in the isolation of strains of pink Cryptococcus, Cladosporium herbarum and another Cladosporium species, Penicillium roseo-citreum, Aspergillus fumigatus, a species of Nigrospora and an unidentifiable fungus with a sterile mycelium. Plates similarly inoculated from seven other lesions remained sterile. Skin tests with saline suspensions of heat-killed organisms from forty-eight hour growths on Sabouraud's glucose agar slants resulted in immediate reactions to all the strains except the Cryptococcus. No late reactions appeared in the test areas, but focal exacerbations of the patient's lesions occurred after both intracutaneous and subcutaneous injections. Cutaneous sensitivity to each of the six fungi was passively transferred to the skin of three normal 
individuals. The sensitivity was exhibited by the formation of wheals. By the methods of in vivo and in vitro reagin neutralization, only a single reagin could be demonstrated for three species: Nigrospora, Cladosporium herbarum and Aspergillus fumigatus. Passive transfer tests were negative to Trichophytin (Metz), Rhizopus and Saccharomyces cerevisiae but were positive in two of three subjects to Alternaria (from dust) and in two subjects to Monilia albicans extract (Lederle $1: 100$ ).

\section{CONCLUSIONS}

1. In the patient described there was definite evidence of hypersensitivity to six of the saprophytic molds cultured from the skin. There is reason to believe that this hypersensitivity was an important factor in the development of his dermatosis.

2. Saprophytic fungi should be regarded as possible incitants of allergic dermatoses, as well as of hay fever and asthma.

3. The reciprocal neutralization of reagin by imperfect fungi of three widely separated genera indicates that this test may be of value in the study of the non-pathogenic molds. Other instances of multiple sensitivity to these fungi must be found, however, before definite conclusions can be drawn.

\section{BIBLIOGRAPHY}

1. Benham, R. W., and Hopkins, A. McH., Yeastlike fungi found on the skin and in the intestines of normal subjects. Arch. Dermat. and Syph., 1933, 28, 532.

2. Benham, R. W., Cryptococci-their identification by morphology and by serology. J. Infect. Dis., 1935, 57, 255.
3. Coca, A. F., and Grove, E. F., Studies in hypersensitiveness. XIII. A study of the atopic reagins. J. Immunol., 1925, 10, 445.

4. Hilgermann, Die Therapie und Aetiologie der chronischen Hautekzeme. München. med. Wchnschr., 1921, 68, 702.

5. Hopkins, J. G., Kesten, B. M., and Benham, R. W., Sensitization to saprophytic fungi in a case of eczema. Proc. Soc. Exper. Biol. and Med., 1930, 27,342 .

6. Hopkins, J. G., Benham, R. W., and Kesten, B. M., Asthma due to a fungus-alternaria. J. A. M. A., 1930, 94, 6.

7. Hopkins, J. G., and Benham, R. W., Specific sensitivity in eczema. Compt. rend. Cong. internat. de dermat. et de Syph., 1930, p. 602.

8. Brown, G. T., Sensitization to fungi. Ann. Int. Med., 1932, 6, 655.

9. Bernton, H. S., Asthma due to a mold-aspergillus fumigatus. J. A. M. A., 1930, 95, 189.

10. Flood, C. A., Observations on sensitivity to dust fungi in patients with asthma. J. A. M. A., 1931, 96, 2094.

11. Jimenez-Diaz, C., Cuenca, B. S., and Puig, J., Climatic asthmas. J. Allergy, 1932, 3, 396.

12. Rackemann, F. M., and Stevens, A. H., Skin tests to extracts of echinococcus and ascaris. J. Immunol., 1927, 13, 389.

13. Brunner, M., Immunological studies in human parasitic infestation. I. Intradermal testing with parasitic extracts as an aid in the diagnosis of parasitic infestation. J. Immunol., 1928, 15, 83.

14. Sulzberger, M. B., and Kerr, P. S., Trichophytin hypersensitiveness of urticarial types with circulating antibodies and passive transference. J. Allergy, 1930, 2, 11.

15. Tomlinson, W. J., Trichophytin hypersensitiveness. Report of a case with an immediate or reaginogenic type of reaction. J. Allergy, 1935, 6, 573.

16. Sulzberger, M. B., Experiments in passive transference of urticarial hypersensitiveness to fungous extracts. J. Immunol., 1932, 23, 73. 